\title{
Effectiveness Demand Forecasting Analysis for XYZ Brand Jeans (Case Study in PTGP)
}

\author{
Ezra Diamond Christo Purwanto ${ }^{1}$, Nofrisel $^{2}$ \\ \{ezradiamond@gmail.com ${ }^{1}$, nofrisel@yahoo.com ${ }^{2}$ \} \\ University of Indonesia, Jakarta, Indonesia ${ }^{1,2}$
}

\begin{abstract}
The textile and apparel industry is a rapidly developing industry and has an influence on the Indonesian economy. Despite having high competition, the textile and apparel industry is one of the interesting industries to be made into business opportunities in several big cities. PTGP is a company that has taken business opportunities in the apparel industry for decades. Companies in the mature category are not always successful in doing business. PTGP must close the business branches owned because operating costs are higher than the revenue generated from sales. Efficient operational costs are needed by every company in carrying out the company's operations. Forecasting is a way that can be used for the company's operational effectiveness and operational cost efficiency. The right time series forecasting method can be determined by looking at the historical data of demand for the product. Accuracy is the main factor used as a condition for selecting the forecasting method to be used. Single Exponential Smoothing is a forecasting method used in general in various industrial fields using historical data. Holt's Model is a forecasting method used with the influence of trends in the data used. Winter's Model is a forecasting method that is used in the presence of trend and seasonal influences on the data used. The forecasting errors generated were $14.38 \%$ for the Single Exponential Smoothing method, $10.34 \%$ for Holt's Model, and $15.65 \%$ for the Winter's Model, so the use of Holt's Model forecasting was more recommended in the textile and apparel industry.
\end{abstract}

Keywords: Forecasting, Forecasting Method, Time Series, Single Exponential Smoothing, Holt's Model, Winter's Model

\section{Introduction}

The Textile and Apparel Industry is one of the leading businesses in several big cities in Indonesia, such as DKI Jakarta, East Java, Banten and Central Java. Changes in fashion make sales even faster so sellers of clothing products tend to react quickly to changing market preferences and offer trendy products to meet customer needs. They must respond quickly to customer requests because of the characteristics of products offered by fast fashion companies such as short product life cycles, relatively simple product designs, and high demand uncertainty [1]. Based on the statistical data of the Quarterly Gross Domestic Product provided by the Indonesian Central Bureau of Statistics, the Indonesian Textile and Apparel Industry for 2014-2017 continues to grow each year compared to the annual and quarterly basis which can be seen in Figure 1. From Figure 1 we can see the growth of the Indonesian Textile and Garment Industry for 2014-2017 experiencing steady growth in every year. This 
growth can be seen from the number in the first quarter compared to the fourth quarter of each year.

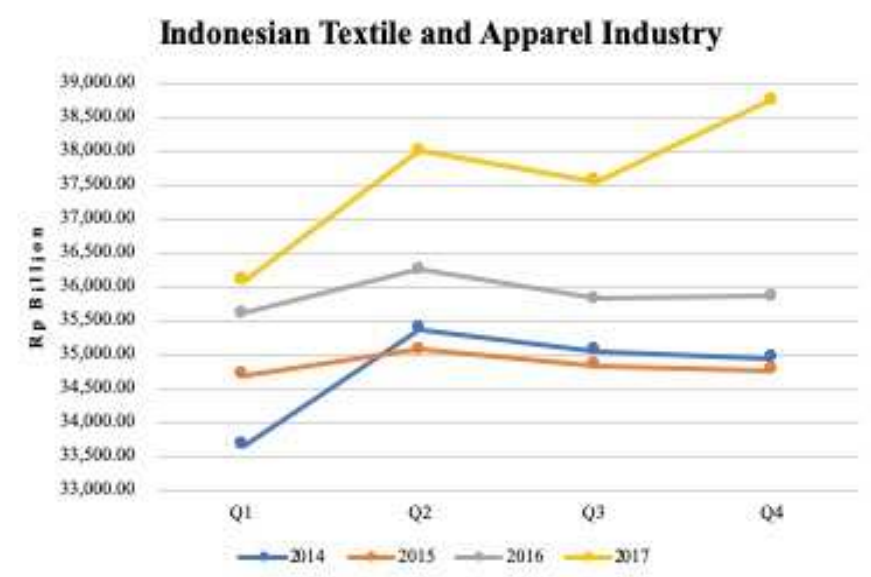

Figure 1. Graph of Quarterly Gross Domestic Product Growth of Textile and Apparel Industry in Indonesia 2014-2017

Even though according to the statistical data of the Quarterly Gross Domestic Product provided by the Indonesian Central Bureau of Statistics for the Indonesian Textile and Apparel Industry for 2014-2017 the numbers have experienced steady growth in each year, but if noted in more detail, based on data on Domestic Product Growth Rate Quarterly Gross, the growth rate of the Indonesian Textile and Garment Industry for 2014-2017 could be said to be unstable for every year that can be seen from Figure 2. The unstable changes in Indonesian textile and apparel industry for the years 2014-2017 occur with significant growth rate in the second quarter for each year.

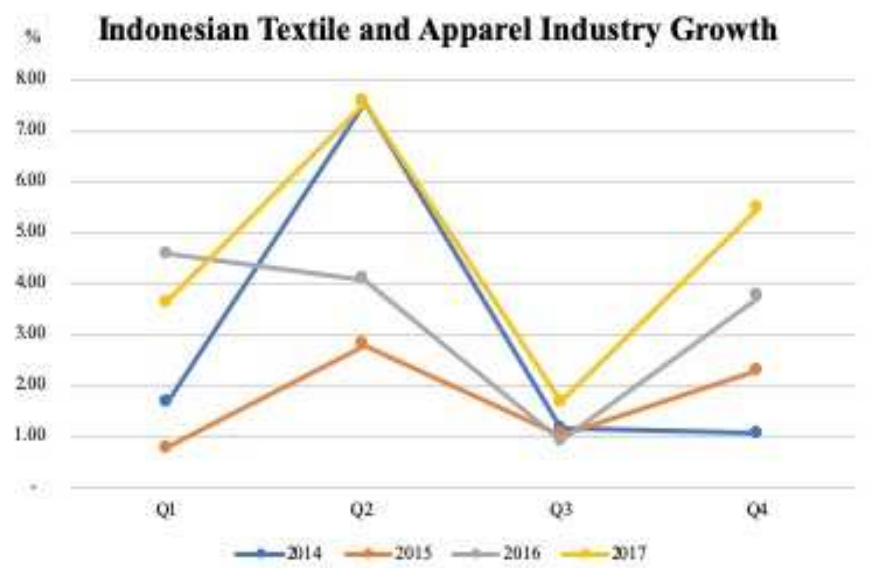

Figure 2. Graph of Quarterly Gross Domestic Product Growth Rate of Textile and Apparel Industry in Indonesia 2014-2017 
As the sole manufacturer of XYZ brand jeans, PTGP must be able to provide supply for distributors, both at the department store and retail scale, to meet unstable consumer demand. To deal with these uncertainties, demand forecasting is used because it becomes important in company decision making that is used as the references for mid-term and long-term planning. Forecasting is used in every functional area within the company. In the field of finance, forecasting is used as a reference for budget planning and cost control. In the field of marketing, forecasting is used as a reference for planning a new product and in the operational field, forecasting is used as a reference for making decisions in the company productivity [2]. Demand forecasting is one of the important things in the clothing business because there is uncertainty in demand and supply [3] and clothing companies must have production, inventory, and planning with various decisions based on forecasting with short lead times [1].

The purpose of this paper is to get the right forecasting method to be used in the clothing industry and can be used by PTGP to forecast demand for XYZ brand jeans. Forecasting demand for XYZ brand jeans in PTGP is done using Single Exponential Smoothing method, Holt's Model, and Winter's Model. Demand forecasting results are analyzed by the accuracy and we choose the best method compared to the forecasting method used by PTGP at this time. This paper is expected to determine the right forecasting method for companies in the apparel industry and give advice to PTGP as a considerations of the demand forecasting method for XYZ brand jeans so could reduce operational and inventory costs to obtain product competitiveness in the apparel market and increase company profits.

\section{Forecasting}

Every decision taken, before fulfilling demand, needs to be forecasted which is one of the important things in a company plan. By doing forecasting, companies can have guidelines for decision making in carrying out management strategies so that the products produced by the company can compete in the market so that the products produced can provide maximum benefits to the company. When each stage in the supply chain makes each forecast, the results of forecasting will be very different so there is a mismatch between supply and demand. However, when all stages in the supply chain work together to collaboratively forecast, the forecasting results tend to be more accurate so that the forecasting accuracy produced enables the supply chain to be more responsive and efficient in meeting customer demand [4]. In doing forecasting there are several characteristics that need to be understood, such as a) the results of forecasting are always inaccurate so that forecasting must include the desired forecasting value and measurement of forecasting errors. Forecasting errors which are uncertainties of demand are the main input into most supply chain decisions, b) the results of long-term forecasting can be said to be less accurate than the results of short-term forecasting. This is because long-term forecasting has a standard deviation error greater than the average of short-term forecasting results, c) using aggregate forecasting will provide more accurate results than using disaggregate forecasting. Aggregate forecasting tends to have a smaller standard deviation than the average, and d) the further company's supply chain from consumers, the greater distortion of information the company received. One example of information distortion is a bullwhip effect where variations in demand are stronger when demand moves farther than the final customer. Collaborative forecasting based on sales to end consumers can help companies reduce forecasting errors [5]. Companies may difficult to determine which method is most appropriate for forecasting. The results of several studies 
have indicated that using several forecasting methods to make combined forecasting more effective than just using one forecasting method [5].

To forecast demand, companies must first identify the factors that influence demand in the future and then ensure the relationship between these factors of influence with future demand. Companies must balance between objective and subjective factors when forecasting demand, and must be knowledgeable about various factors related to demand forecasting, such as demand history, time needed to refill products, marketing plan efforts, price discount plans, and actions taken by competitors. Companies must understand these factors before choosing the right forecasting methodology with the company's targets [5]. Forecasting methods can be classified into four types of methods: a) Qualitative method that prioritizes subjectivity and relies on human judgment, b) Time-series method which is used historical data to forecast based on assumption that historical demand is a good indicator for future demand, c) Causal method which is assumed that demand forecasting is closely related to certain factors in the environment, such as economic conditions, interest rates, etc., and d) Simulation method which mitates customer choices that give rise to demand and arrive at forecasting [5].

In this paper we use time series forecasting methods to get forecast results in the future. The time-series forecasting model tries to predict the future based on past data. Which forecasting model should the company choose depends on the forecast time span, data availability, accuracy, large budget estimates, and availability of human resources [2]. Timeseries forecasting methods are included in adaptive forecasting methods that have four forecasting methods, they are a) Moving Average method, which is used when demand do not have observable trends or seasons, b) Single Exponential Smoothing method, which is appropriate when the demand has no observable trend or season, c) Trend-Corrected Exponential Smoothing method (Holt's model), which is corrected according to the time when demand is assumed to have levels and trends in a systematic component, but there is no seasonal factor, and d) Trend \& Seasonality-Corrected Exponential Smoothing (Winter's Model), which is appropriate when the systematic demand component has levels, trends, and seasonal factors which are developments from the Holt's Model with additional seasonal factors [5].

\subsection{Single Exponential Smoothing Method}

The initial estimate of level, $\mathrm{L}_{0}$, is taken to be the average of all historical data because demand has been assumed to have no observable trend or seasonality. Given demand data for Periods 1 through n, we have the following:

$$
L_{0}=\frac{1}{n} \sum_{i=1}^{n} D_{i}
$$

The current forecast for all future periods is equal to the current estimate of level and is given as:

$$
F_{t+n}=L_{t}
$$

After observing the demand, $D_{t+1}$, for Period $t+1$, we revise the estimate of the level as follows:

$$
L_{t+1}=\alpha D_{t+1}+(1-\alpha) L_{t}
$$


The formula $L_{t+1}$ is the level in the period $\mathrm{t}+1$ which is obtained from the sum of demand $\mathrm{D}_{\mathrm{t}+1}$ with proportion $\alpha$ and level period $\mathrm{t}$ with proportion $1-\alpha$, where $\alpha(0<\alpha<1)$ is a smoothing constant for the level.

\subsection{Holt's Model}

We obtain an initial estimate of level and trend by running a linear regression between demand, Dt, and time, Period t, of the form:

$$
D_{t}=a t+b
$$

In Period t, given estimates of level $\mathrm{Lt}$ and trend $\mathrm{Tt}$, the forecast for future periods is expressed as:

$$
F_{t+n}=L_{t}+n T_{t}
$$

After observing demand for Periode t, we revise the estimates for level and trend as follows:

$$
\begin{aligned}
& L_{t+1}=\alpha D_{t+1}+(1-\alpha)\left(L_{t}+T_{t}\right) \\
& \left.T_{t+1}=\beta\left(L_{t+1}-L_{t}\right)+(1-\beta) T_{t}\right)
\end{aligned}
$$

Where $\alpha(0<\mathrm{a}<1)$ is a smoothing constant for the level and $\beta(0<\beta<1)$ is a smoothing constant for the trend.

\subsection{Winter's Model}

In Period t, given estimates of level, Lt, trend, Tt, and seasonal factors, St, the forecast for future periods is given by:

$$
F_{t+n}=\left(L_{t}+n T_{t}\right) S_{t+n}
$$

On observing demand for Period $\mathrm{t}+1$, we revise the estimates for level, trend, and seasonal factors as follows:

$$
\begin{aligned}
& L_{t+1}=\alpha\left(D_{t+1} / S_{t+1}\right)+(1-\alpha)\left(L_{t}+T_{t}\right) \\
& \left.T_{t+1}=\beta\left(L_{t+1}-L_{t}\right)+(1-\beta) T_{t}\right) \\
& \left.S_{t+p+1}=\gamma\left(D_{t+1} / L_{t+1}\right)+(1-\gamma) S_{t+1}\right)
\end{aligned}
$$

Where $\alpha(0<\mathrm{a}<1)$ is a smoothing constant for the level; $\beta(0<\beta<1)$ is a smoothing constant for the trend; and and $\gamma(0<\gamma<1)$ is a smoothing constant for the seasonal factor. 


\section{Result and Analysis}

Historical data recapitulated in Table 1 was actual data on demand from PTGP cutomers for XYZ brand jeans, both department stores and retailers starting in August 2014 to July 2018. The historical data for the request is then divided into four periods of demand, namely Period I ( August 2014 - July 2015), Period II (August 2015 - July 2016), Period III (August 2016 - July 2017), and Period IV (August 2017 - July 2018).

Table 1. Historical Data for XYZ Brand Jeans Demand

\begin{tabular}{lllll}
\hline & Periode I & Periode II & Periode III & Periode IV \\
\hline Agustus & 6,669 & 3,968 & 4,025 & 4,275 \\
September & 3,981 & 3,770 & 4,124 & 4,574 \\
Oktober & 3,832 & 4,861 & 5,217 & 5,667 \\
November & 4,131 & 4,663 & 5,018 & 5,468 \\
Desember & 8,958 & 9,227 & 9,937 & 10,937 \\
Januari & 5,076 & 5,258 & 5,664 & 6,264 \\
Februari & 4,280 & 4,762 & 5,167 & 5,667 \\
Maret & 4,180 & 4,861 & 5,664 & 6,264 \\
April & 4,429 & 4,663 & 6,161 & 6,761 \\
Mei & 4,230 & 6,295 & 12,163 & 13,303 \\
Juni & 26,426 & 31,475 & 28,381 & 31,041 \\
Juli & 8,809 & 4,197 & 3,478 & 3,778 \\
\hline
\end{tabular}

Based on Table 4.1, the historical recapitulation of demand can be described graphically in Figure 3.

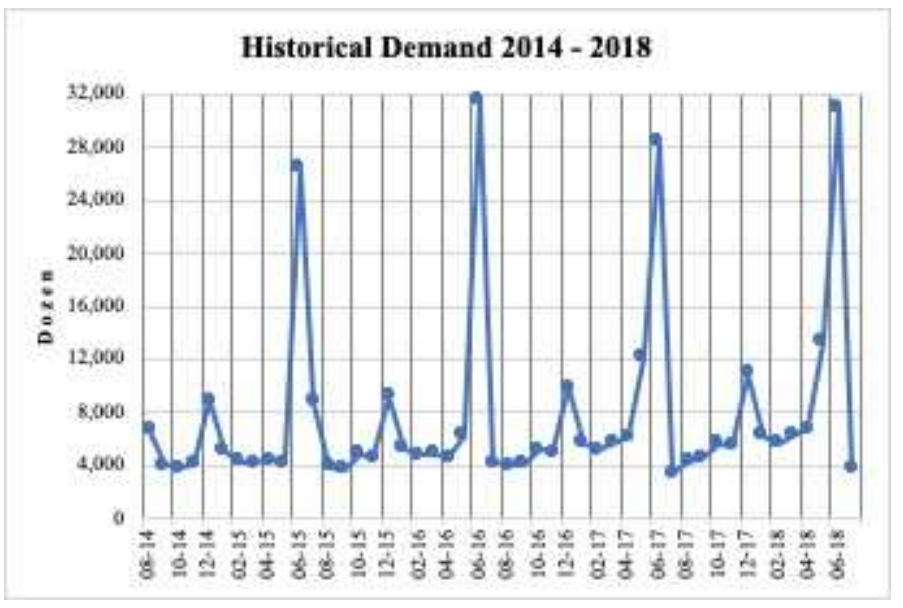

Figure 3. Graph of Historical Demand for XYZ Brand Jeans from August 2014 to July 2018

In Figure 3 can be seen that there were same demand patterns for each period for XYZ brand jeans. From the graph, we can see the change in demand that occurred due to the momentum of Eid al-Fitr in June and Christmas Day in December for each period of demand. 


\subsection{Single Exponential Smoothing Method}

Single Exponential Smoothing forecasting method was used to forecast each period using historical data from previous period demand. As the initial demand data, the formula equation (1) is used which is then used to calculate the next period demand by using the equations of formulas (2) and (3).

Forecasting calculations for Period II use demand historical data for Period I, the results obtained with the following Figure 4:

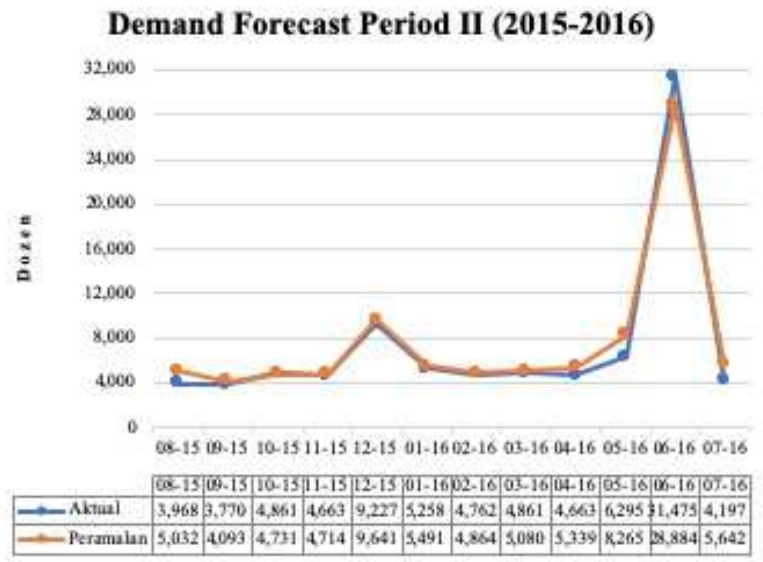

Figure 4. Demand Forecast Period II Using Single Exponential Smoothing

Forecasting calculations for Period III use demand historical data for Period II, the results obtained with the following Figure 5:

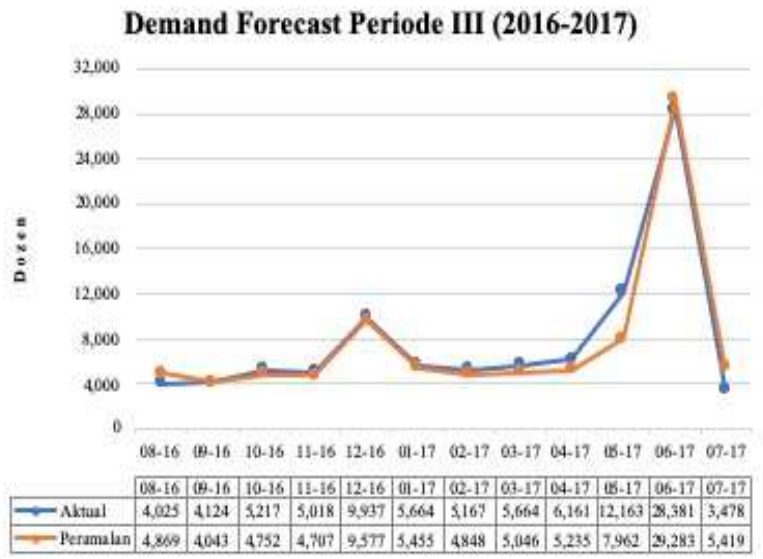

Figure 5. Demand Forecast Period III Using Single Exponential Smoothing 
Forecasting calculations for Period IV use demand historical data for Period III, the results obtained with the following Figure 6:

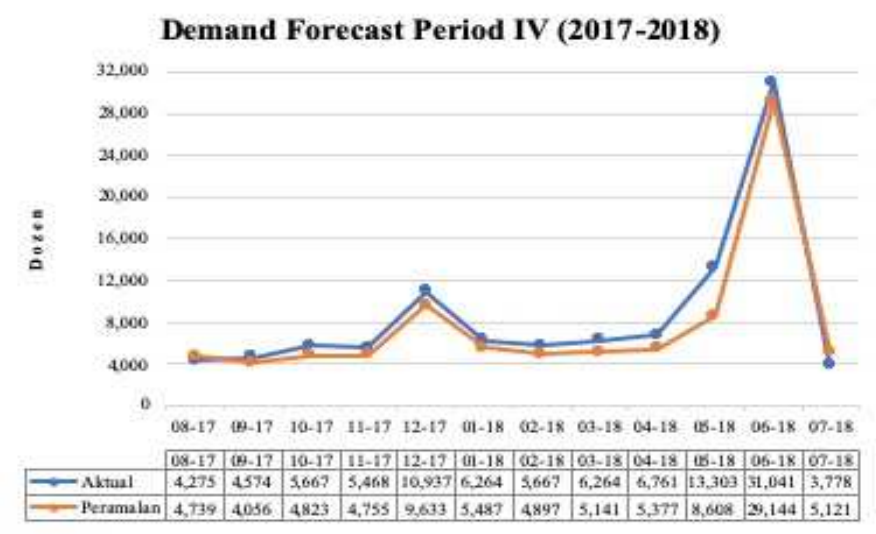

Figure 6. Demand Forecast Period IV Using Single Exponential Smoothing

\subsection{Holt's Model}

Holt's Model forecasting method is used to forecast each period based on historical demand data and also influenced by the change trend. The initial request value is determined using the formula equation (4) which then the calculation results are used to calculate the next period demand forecast using the formula equation (5). To calculate the formula equation (5), it is necessary to calculate the formula equation (6) by using the smoothing constant alpha and formula equation (7) using constant beta smoothing as a trend change value.

Forecasting calculations for Period II use demand historical data for Period I, the results obtained with the following Figure 7:

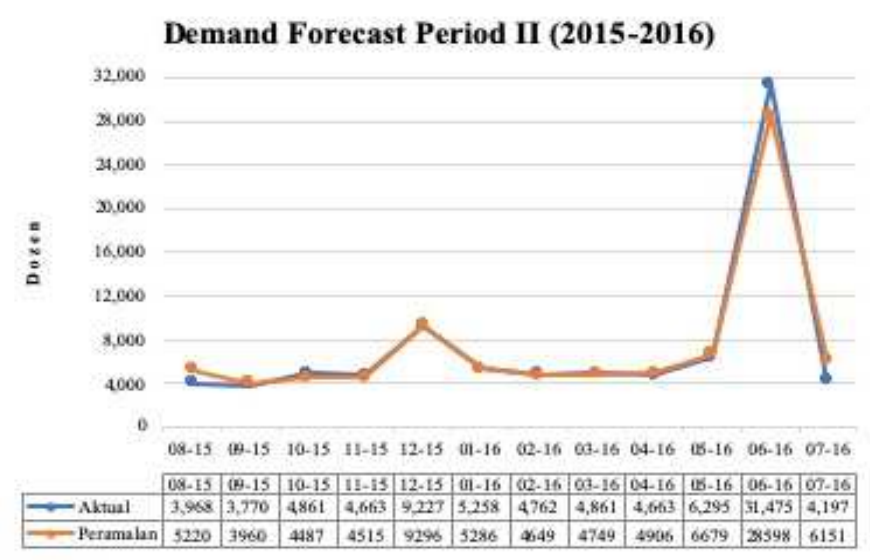

Figure 7. Demand Forecast Period II Using Holt's Model 
Forecasting calculations for Period III use demand historical data for Period II, the results obtained with the following Figure 8:

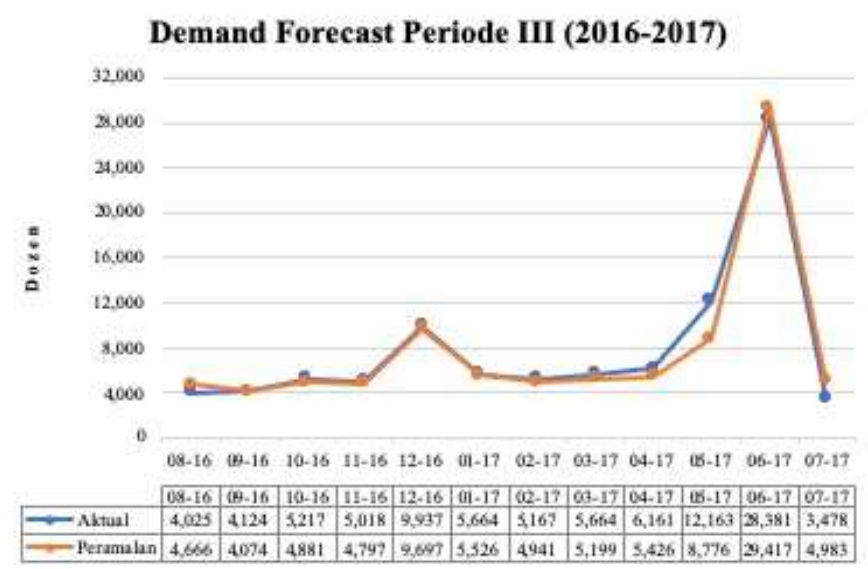

Figure 8. Demand Forecast Period III Using Holt's Model

Forecasting calculations for Period IV use demand historical data for Period III, the results obtained with the following Figure 9:

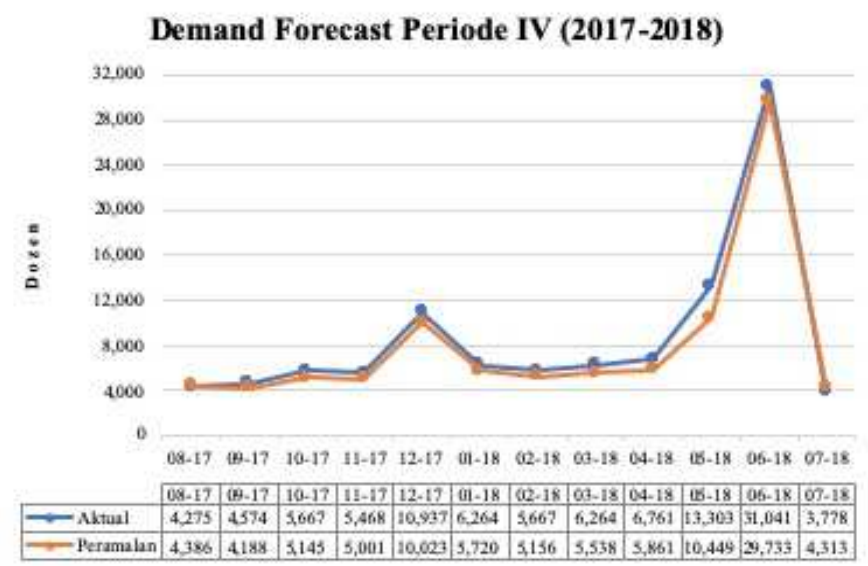

Figure 9. Demand Forecast Period IV Using Holt's Model

\subsection{Winter's Model}

Winter's Model forecasting method is used to forecast each period based on historical demand data, also influenced by trends in changes and seasonal factors. The calculation of demand forecasting for the next period uses the formula equation (8) by calculating the formula equation (9) using smoothing 
constant alpha, formula equation (10) using constant beta smoothing as a trend change value, and formula equation (11) using smoothing constant gamma as the value of seasonal factors.

Forecasting calculations for Period II use demand historical data for Period I, the results obtained with the following Figure 10:

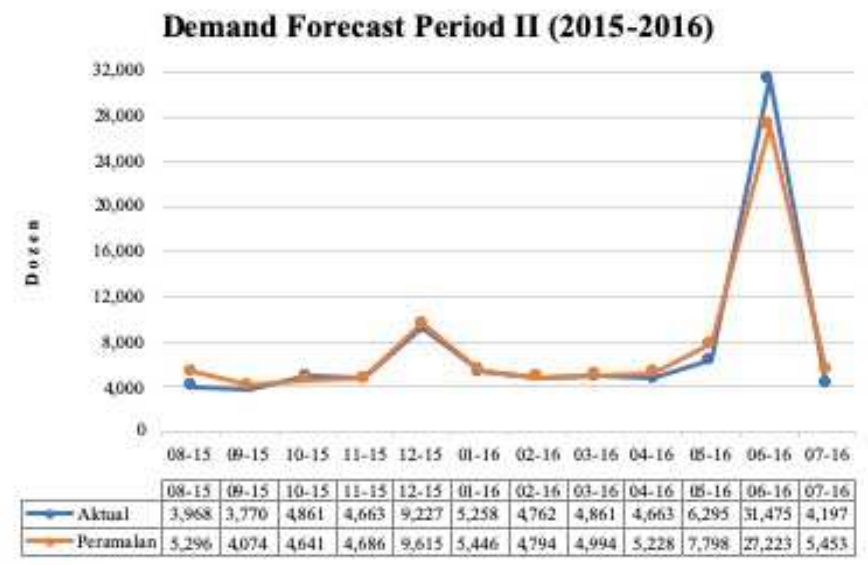

Figure 10. Demand Forecast Period II Using Winter's Model

Forecasting calculations for Period III use demand historical data for Period II, the results obtained with the following Figure 11:

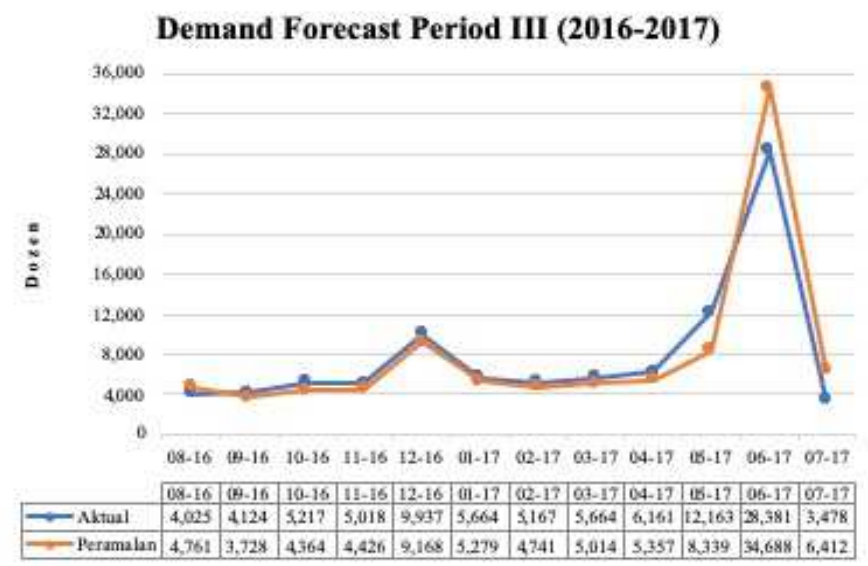

Figure 11. Demand Forecast Period III Using Winter's Model

Forecasting calculations for Period IV use demand historical data for Period III, the results obtained with the following Figure 12: 


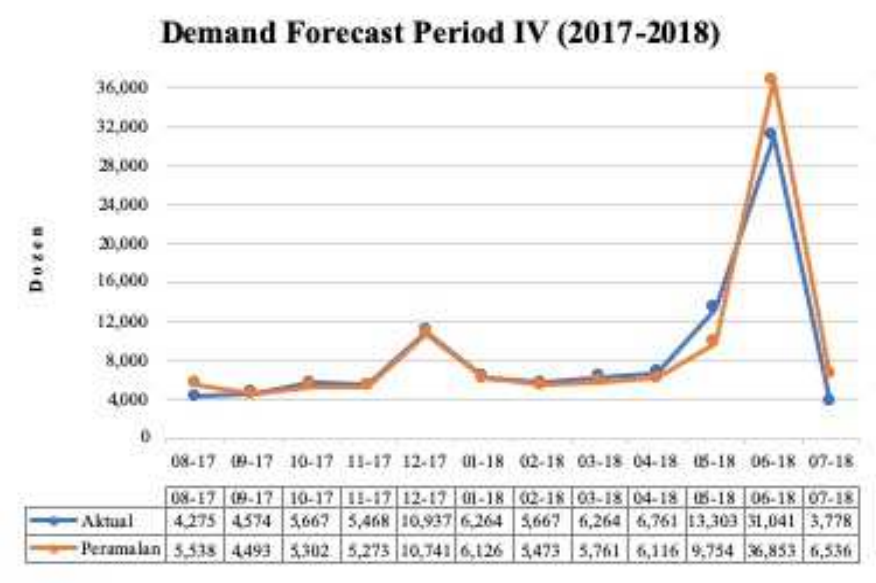

Figure 12. Demand Forecast Period IV Using Winter's Model

Demand forecasting using the Single Exponential Smoothing method, the Holt's Model, the Winter's Model, and the calculations results of MSE, MAD, and MAPE are shown in Table 2 .

Table 2. Forecasting Accuracy Result

\begin{tabular}{lccc}
\hline & MSE & MAD & MAPE \\
\hline Single Exponential Smoothing & $2,074,510$ & 1,006 & $14.38 \%$ \\
Holt's & $1,219,394$ & 736 & $10.34 \%$ \\
Winter's & $4,101,263$ & 1,238 & $15.65 \%$ \\
\hline
\end{tabular}

\section{Conclusion}

The results of forecasting analysis, mean squared error (MSE) and mean absolute percentage error (MAPE) are used to measure the accuracy of the forecasting model used [6]. From the results of demand forecasting that have been done using the Single Exponential Smoothing method, the Holt's Model, and the Winter's Model, the results of MSE, MAD, and MAPE calculations in Table 2 are used as determinants of the accuracy of a more effective forecasting method.

From the comparison it was found that the Holt's model has the best accuracy compared to other forecasting methods indicated by the MAPE value of $10.34 \%$. The next best forecasting method is the Single Exponential Smoothing method with MAPE value of 14.38\% and the last position is the Winter's method with the MAPE value of $15.65 \%$. By the calculation of the accuracy, a better method to be applied by PTGP to forecast XYZ brand jeans is the Holt's method. 


\section{References}

[1] S. Ren, H. L. Chan, and P. Ram, "A Comparative Study on Fashion Demand Forecasting Models with Multiple Sources of Uncertainty," Ann. Oper. Res., vol. 257, pp. 335-355, 2017.

[2] F. R. Jacobs and R. B. Chase, Operations and Supply Chain Management, 15th ed. New York: Mc-Graw Hill Education, 2018.

[3] Y. Yu, T. M. Choi, and C. L. Hui, "An intelligent fast sales forecasting model for fashion products," Expert Syst. Appl., vol. 38, pp. 7373-7379, 2011.

[4] A. Harrison, R. van Hoek, and H. Skipworth, Logistics Management and Strategy, 5th ed. Pearson Education Limited, 2014.

[5] S. Chopra and P. Meindl, Supply Chain Management: Strategy, Planning, and Operation, 6th ed. Pearson Education Inc., 2016.

[6] S. Ren, T. M. Choi, and N. Liu, "Fashion sales forecasting with a panel data-based particle-filter model," IEEE Trans. Syst. Man, Cybern. Syst., vol. 45, no. 3, pp. 411-421, 2015. 